\title{
Evaluation of Carotid Artery Stenting with Distal Filter Protection Device
}

\author{
Pankaj Banode ${ }^{1}$ Ashutosh Kharche ${ }^{1}$ \\ ${ }^{1}$ Department of Interventional Radiology, Jawaharlal Nehru Medical \\ College, Sawangi (M), Wardha, Maharashtra, India
}

Address for correspondence Ashutosh Kharche, MD, Department of Interventional Radiology, Jawaharlal Nehru Medical College, Sawangi (M), 102, Shri Shingaar Apts, MP Road, Mulund (E) 400081, Mumbai, Maharashtra, India (e-mail: kharcheashu@gmail.com).

Int J Recent Surg Med Sci 2018;4:57-64

\begin{abstract}
Keywords

- carotid artery stenting

- distal filter protection device

- evaluation of carotid stenting with distal filter

Objectives To assess the use of proximal protection devices in consecutive patients as the preferred means of cerebral embolic protection for primary carotid stenting.

Methods and Results This was a prospective single-center study to evaluate the technical and clinical success of proximal protection devices as the first choice for embolic protection in symptomatic $(\geq 50 \%)$ and asymptomatic $(\geq 70 \%)$ carotid stenosis. Proximal protection devices were used for embolic protection in 115 consecutive patients. No patients were excluded for anatomical reasons. The filter used was of diameters $6 \mathrm{~mm}$ in all cases (Emboshield NAV filter device, Abbotts Healthcare Pvt. Ltd. [Lake Bluff, II]). In all cases, self-expanding closed-cell designed stent was used (X-act closed-cell self-expanding nitinol carotid-tapered stent, Abbotts Healthcare Pvt. Ltd.). Plaque characterization was done by using real-time high-resolution ultrasound (HR USG) equipment (Aloka Prosound Alpha 7 [Chiyoda, Tokyo, Japan]) using high-frequency linear transducers (> $7 \mathrm{MHz}$ ). Follow-up duration was 30 days. Mean age was $61.9 \pm 8.27$ years. There was male predominance observed in study accounting for 73 out of total 115 studied population. Fifty-six of $115(48.89 \%)$ treated stenoses were symptomatic. Technical success was achieved in 115 of 115 (100\%) cases. In both the cases, additional distal filter devices were used. Carotid stenting was successful in $115(100 \%)$ lesions. This study observed higher number of debris in symptomatic and high-risk plaques. This study also observed higher sensitivity, specificity, and accuracy of updated classification for assessing risk of microembolism (captured debris) (sensitivity $73.91 \%$, specificity $95.65 \%$, positive predictive value [PPV] 91.89\%, negative predictive value [NPV] $84.62 \%$, accuracy $86.95 \%$ ). In our study, minor stroke was seen in three $(2.61 \%)$ patients within 48 hours, and no adverse events were seen within 48 hours to 1 month.

Conclusion Proximal protection is a safe method as the first choice for embolic protection. It can be used with a high rate of technical success.
\end{abstract}

\section{Introduction}

In this modern era, stroke is considered as the third most common cause of death and major cause of functional impairment, and $30 \%$ of strokes have been attributed to atherosclerotic disease of the extracranial carotid artery. ${ }^{1}$ Carotid artery stenosis and plaque morphology have a direct relationship with occurrence of stroke, especially in elderly age group or those having various comorbid conditionshypertension, diabetes mellitus, and dyslipidaemia ${ }^{2}$-and most evident among smokers. Percutaneous carotid artery stenting (CAS) is the minimal invasive alternative to carotid endarterectomy (CEA) for carotid stenosis. Though CAS has its advantages in several respects relative to endarterectomy,
DOI https://doi.org/

10.1055/s-0038-1677641

ISSN 2455-7420.
(C2018 Medical and Surgical Update Society
License terms

$($ () (1) $\Theta \circledast$ 
both CAS and CEA show risk for embolic stroke. CAS poses a risk of distal cerebral embolization caused by mobilized and migrated plaque fragments as a result of manipulation of guidewire or stent, leading to minor or major stroke, which are clinically significant. This is the limitation and remains a cause of concern. Embolic protection devices (EPDs) are widely used to prevent periprocedural cerebral embolization. Distal protection devices have become "standard of care" during angioplasty and stenting for carotid artery stenosis and are easy to use. In spite of the effective and simple use, the incidences of thromboembolic complications during $\mathrm{CAS}^{3-5}$ are evident. Although these devices are safe and feasible to use, there is no strong evidence of effectiveness of distal protection device in reducing the incidence of plaque migration and embolic complications during CAS. ${ }^{3-5}$

Various studies have shown association of vulnerable plaque with symptomatic carotid stenosis secondary to microemboli, identifying that the plaque morphology might be better predictors of stroke, allowing for more precise selection of patients for carotid stenting with EPD. ${ }^{4}$ The most commonly used existing classification of plaque morphology on highresolution ultrasound/ultrasonography (HR USG) is based on echogenicity of plaque. Though there are various classification systems on HR USG, available for characterization of carotid plaque, these classification systems have limitation in view of its utility to assess risk of embolism, microembolism, and symptoms. Hence, there is need for simplified way of classification that can help in assessing the plaque, which is prone for microemboli from the stable plaque. Therefore, an updated classification system is attempted in present work on HR USG adding the various predictors of vulnerable plaques in addition to existing predictor, echogenicity.

The aim of this study is evaluation of CAS with distal protection device for captured debris in filter and adverse events in relation to type of plaque based on updated classification of plaque morphology.

\section{Material and Methods and Hardware}

\section{Study Design}

This was a prospective, cross-sectional, observational, and analytical study conducted on 115 patients. The sample size of 115 patients was determined based on power analysis at a confidence interval of $95 \%(p<0.05)$. This study was performed from July 2015 to August 2017 for the period of 2 years on 115 patients with carotid artery stenosis (39 females and 76 males) in the age range of 46 to 88 years (with mean age $61.94 \pm 8.27$ years) who have undergone CAS with distal filter protection device (DFPD) in the department of TIFAC-CORE in IR at Acharya Vinoba Bhave Rural Hospital, attached to Jawaharlal Nehru Medical College, Datta Meghe Institute of Medical Sciences (deemed to be university), Sawangi (M), Wardha, Maharashtra, India.

\section{Plaque Characterization}

Plaque characterization was done by using real-time HR USG equipment (Aloka Prosound Alpha 7, Chiyoda, Tokyo, Japan) using high-frequency linear transducers $(>7 \mathrm{MHz}$ ). The $\mathrm{HR}$
USG was performed in supine position with the head slightly hyperextended and rotated 45 degrees away from the side being examined.

\section{Carotid Stenting}

CAS was performed on Philips Allura FD-20 Scanner (Amsterdam, The Netherlands). Preprocedural detailed neurologic examination, color Doppler evaluation, computed tomography/magnetic resonance imaging (CT/MRI) of the brain, and digital subtraction angiography prior to CAS were performed. ${ }^{6,7}$

All patients were premedicated with two oral antiplatelet drugs (aspirin $150 \mathrm{mg}$ daily and clopidogrel $75 \mathrm{mg}$ daily) for at least 3 days before the procedure.

The procedure was performed under local anesthesia through right femoral access in all patients. Intravenous systemic heparinization was performed through vascular access (50-100 IU) to maintain the activating clotting time within 250 to 300 seconds.

After achieving intra-arterial access, a 6F/90-cm-long shuttle sheath (Shuttle Cook, Inc. Lake Bluff, Il) was introduced up to mid part of common carotid artery $\mathrm{y}^{4,5}$ in almost 107 patients. In eight patients because of tortuous vascular anatomy, initial insertion of $5 \mathrm{~F}$ catheter was done into the external carotid artery (ECA) over which long shuttle sheath was exchanged over the exchange wire.

In all cases, extracranial and intracranial angiography was performed to confirm the lesion. Over the sheath, filter assembly was introduced and placed at the straight course of the internal carotid artery (ICA) approximately $2 \mathrm{~cm}$ distal to the lesion. The filter used was of diameters $6 \mathrm{~mm}$ in all cases (Emboshield NAV filter device, Abbotts Healthcare Pvt. Ltd., Lake Bluff, Il). After deployment of delivery catheter, an angiogram was obtained to document blood flow through the filter and to document device placement distal to the target lesion. In two cases with tight lesion morphology, balloon angioplasty was performed with $2.5-\mathrm{mm}$ balloon before placement of filter. In all cases, self-expanding closedcell designed stent was used (X-act closed-cell self-expanding nitinol carotid-tapered stent, Abbotts Healthcare Pvt. Ltd.). Following the completion of the procedure, the filter assembly was recovered using the retrieval catheter that was advanced over the guidewire through the stented lesion. The entire device is then removed from the patient with the captured emboli contained in the filtration element. Post-dilatation was performed in two patients using 4- and 5 -mm balloon as residual stenosis $\geq 30 \%$ was observed. Post-stenting intracranial and extracranial angiography was performed to identify any flow impairment. In the event of bradycardia or hypotension during the procedure, atropine sulfate was used in the appropriate manner. After CAS, the puncture site was treated with manual compression. Patients were then transferred to the intensive care unit or special care unit and monitored for any neurologic symptoms. The retrieved filter was sent for pathologic evaluation.

Patients were prescribed clopidogrel for 30 days after CAS and aspirin for lifelong. Patients were evaluated for minor stroke, major stroke, myocardial infarction (MI), and death 
immediately after the procedure, during hospital stay, and after 30 days of the procedure.

\section{Distal Embolic Protection Device}

All eligible patients underwent CAS with distal protection device using Emboshield NAV filter device, Abbotts Vascular Healthcare Pvt. Ltd. It is a flow preservation devicesDFPD that is most commonly used for neuroprotection. DFPD allows antegrade cerebral flow during the entire procedure.

\section{Filter Designs}

The device ( $\boldsymbol{- \text { Fig. }} \mathbf{1}$ ) is advanced over a 0.014 -in wire with crossing profiles ranging from 2.8 to 3.2F. It is used for vessel size of 2.5 to $7.0 \mathrm{~mm}$ and having pore size of $140 \mu \mathrm{m}$. The main limitations of this device are related to the need to cross the lesion with the wire and filter before initiating protection. The device is associated with potential adverse events such as abrupt closure, allergic reactions, filter thrombosis/ occlusion, and stent/filter entanglement/damage. The complications associated with EPD, as mentioned in the literature, include filter entanglement, vasospasm, arterial dissection trapped guidewire, and difficult retrieval.

\section{Filter Analysis}

Filters were collected and evaluated for macroscopic (qualitative) presence of debris. Filters were then placed within Cytolyt containers that were used to stir rinsing debris particles off the filter membrane. The debris collected was prepared using the automated thin-prep system and a thin layer of cells on a glass slide. Light microscopy of 22 optic fields under the computerized TIS (thin-prep imaging syste operation summary and clinical information) was used for examination of the slides.

\section{Definition}

In this study, technical success was defined as successful deployment and retrieval of filter and successful placement of stent. Minor stroke was defined as the sudden onset of a neurologic deficit lasts for $\geq 24$ hours with complete recovery. Major stroke was defined as sudden onset of a neurologic deficit (National Institutes of Health Stroke Scale [NIHSS] $\geq 9$ ) persisting for a minimum of 30 days.

\section{Statistical Analysis}

Statistical analysis was done by using descriptive and inferential statistics using chi-square test and software used in the analysis were SPSS version 22.0 and Graph Pad Prism version 6.0 , and $p<0.05$ was considered as level of significance.

\section{Results}

This study observed higher number of captured debris (microscopic and visible) in high-risk plaque compared with low-risk plaque $(p=0.0001, \mathrm{~S}, p<0.05)$. Higher number of absent captured debris in EPD was seen in low-risk plaque. In low-risk plaque, 26\% $(n=12)$ cases showed captured debris that were mostly associated with calcification protruding into lumen, as shown in - Table 1.

This study observed higher sensitivity, specificity, and accuracy of updated classification for assessing risk of microembolism (captured debris) (sensitivity 73.91\%, specificity $95.65 \%$, positive predictive value [PPV] $91.89 \%$, negative predictive value [NPV] $84.62 \%$, accuracy $86.95 \%$ ). When compared with existing classification, the updated classification shows higher sensitivity, specificity, and accuracy (existing classification-sensitivity $70.27 \%$, specificity 67.95\%, PPV 50.98\%, NPV 82.81\%, accuracy 68.69\%). This study observed superiority over updated classification over existing classification.

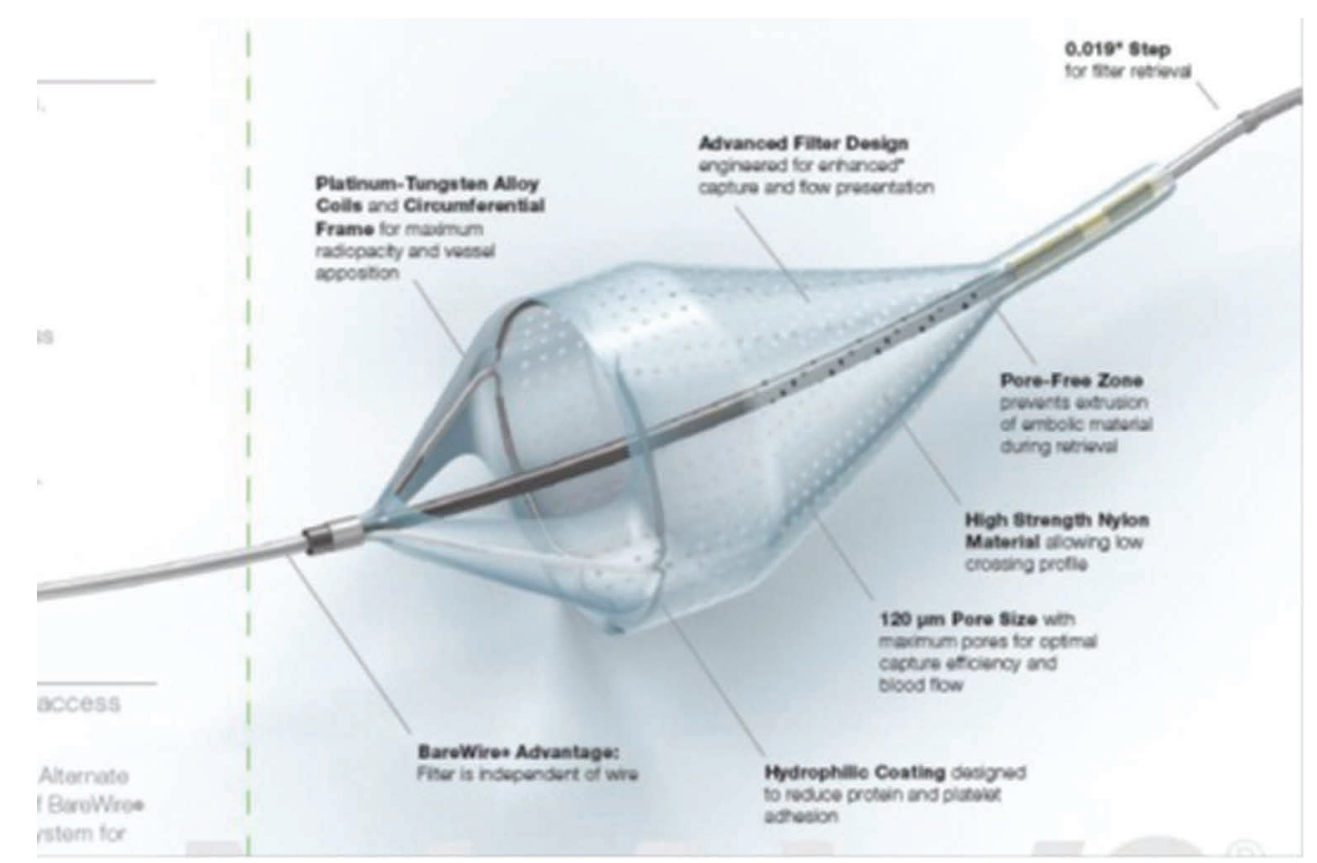

Fig. 1 Emboshield NAV distal protection device. 
Table 1 Predicted values of individual plaque predictors in updated classification of plaque morphology

\begin{tabular}{|c|c|c|c|c|c|}
\hline \multirow[t]{2}{*}{ Risk factors } & \multicolumn{2}{|c|}{ Plaque morphology } & \multirow[t]{2}{*}{ Total } & \multirow[t]{2}{*}{$\chi^{2}$} & \multirow[t]{2}{*}{ Value } \\
\hline & Low risk & High risk & & & \\
\hline \multirow[t]{2}{*}{ Echogenicity } & $42(91.30 \%)$ & $14(20.29 \%)$ & $56(48.70 \%)$ & \multirow[t]{2}{*}{55.71} & \multirow[t]{2}{*}{$0.0001, \mathrm{~S}$} \\
\hline & $4(8.70 \%)$ & $55(78.71 \%)$ & $59(51.30 \%)$ & & \\
\hline \multirow[t]{2}{*}{ Calcification } & $40(86.96 \%)$ & $2(2.90 \%)$ & $42(36.52 \%)$ & \multirow[t]{2}{*}{84.11} & \multirow[t]{2}{*}{$0.0001, \mathrm{~S}$} \\
\hline & $6(13.04 \%)$ & $67(97.10 \%)$ & $73(63.48 \%)$ & & \\
\hline \multirow[t]{2}{*}{ Ulceration } & $43(93.48 \%)$ & $45(65.22 \%)$ & $88(76.52 \%)$ & \multirow[t]{2}{*}{12.27} & \multirow[t]{2}{*}{$0.0001, \mathrm{~S}$} \\
\hline & $3(6.52 \%)$ & $24(34.78 \%)$ & $27(23.48 \%)$ & & \\
\hline \multirow{2}{*}{$\begin{array}{l}\text { Intraplaque } \\
\text { hemorrhage }\end{array}$} & $46(100 \%)$ & $52(75.36 \%)$ & $97(84.35 \%)$ & \multirow[t]{2}{*}{13.29} & \multirow[t]{2}{*}{$0.0001, \mathrm{~S}$} \\
\hline & $0(0 \%)$ & $17(24.64 \%)$ & $17(14.78 \%)$ & & \\
\hline \multirow[t]{3}{*}{ Plaque vascularity } & $46(100 \%)$ & $60(86.96 \%)$ & $106(92.17 \%)$ & \multirow[t]{2}{*}{6.50} & \multirow[t]{2}{*}{$0.011, \mathrm{~S}$} \\
\hline & $0(0 \%)$ & $9(13.04 \%)$ & $9(7.83 \%)$ & & \\
\hline & Sensitivity & Specificity & PPV & NPV & Accuracy \\
\hline Echogenicity & $91.30 \%$ & $78.71 \%$ & $75.00 \%$ & $93.22 \%$ & $84.34 \%$ \\
\hline Calcification & $86.96 \%$ & $97.10 \%$ & $95.24 \%$ & $91.78 \%$ & $93.04 \%$ \\
\hline Ulceration & $93.48 \%$ & $34.78 \%$ & $48.86 \%$ & $88.89 \%$ & $58.26 \%$ \\
\hline $\begin{array}{l}\text { Intraplaque } \\
\text { hemorrhage }\end{array}$ & $100 \%$ & $24.64 \%$ & $46.94 \%$ & $100 \%$ & $54.78 \%$ \\
\hline Plaque vascularity & $100 \%$ & $13.04 \%$ & $43.40 \%$ & $100 \%$ & $47.82 \%$ \\
\hline
\end{tabular}

Abbreviations: NPV, negative predictive value; PPV, positive predictive value.

\section{Discussion}

Literature suggests most evidence of slightly higher incidence of preoperative strokes in the non-protected group. The risk of migration and dislodgement of microemboli is possible during any stage of CAS such as crossing the lesion, predilatation/angioplasty, stent placement/deployment, and post-stent deployment. Protection devices have been designed to reduce the risk of distal microemboli migration while performing CAS. With evolution of technology in the field of USG and MRI/magnetic resonance angiography (MRA) and increase in the sensitivity and specificity of detection of stenosis, their noninvasiveness, radiation-free nature, low cost, and high availability have made them better choice for diagnosis and treatment planning. Digital subtraction angiography (DSA) still remains the gold standard for reference where USG and MRA fail to diagnose or in cases of dilemma, but being an invasive modality, it is reserved for therapeutic approach. ${ }^{8-10}$ As most of the study shows significant relation between plaque morphology and risk of microemboli and stroke, plaque characterization is crucial part of imaging of the atherosclerotic carotid stenosis. There are various ways to evaluate plaque morphology, B-mode USG, contrast-enhanced USG (CEUS), CT, MRI, positron emission tomography (PET), and intravascular ultrasound, each having its advantage and limitations. B-mode HR USG has major advantage of easy availability and cost-effectiveness with comparable imaging capability.

It has been shown that echolucent plaques have increased lipid and cholesterol level, which makes them unstable and prone to ulceration and embolization. Similarly, plaques with a lipid-rich necrotic core and intraplaque hemorrhage (IPH) are features of a so-called vulnerable plaque, and its relevance has been consistently demonstrated in symptomatic carotid stenosis. ${ }^{11}$ In contrast, echogenic plaques contains significantly more fibrin and collagen that makes them stable and rendering them less likely to embolize. ${ }^{12,13}$

The importance of these various predictors (calcification, ulceration, IPH, and plaque vascularity) for assessing plaque vulnerability was suggested in various studies and evaluated on imaging modalities such as CT, HR USG, MRI, and CEUS. ${ }^{16-20}$ Advances in CAS are likely to continue and will be related to the systems used to introduce equipment into the carotid artery, embolic protection, and stent design. Of all these areas, the majority of advancements to date have been in the design of EPDs, which are now specifically engineered for CAS. CAS has been made safer because of these advances, and further development of these devices will likely lead to continued improvements in the safe performance of this procedure. ${ }^{3-5}$

Existing classification: B-mode HR USG classified plaque into four types:

Type 1: Predominantly echolucent

Type 2: Substantially echolucent with small area of echogenicity

Type 3: Predominantly echogenic with small area of echolucency

Type 4: Uniformly echogenic

\section{Limitation of Existing Classification}

It has considered single parameter for classification and hence is subjective. It does not consider other parameters or 
predictors such as ulceration, IPH, calcification, and plaque vascularity that are important parameters as studied by various authors. Although significant relation of echolucency and stroke-related symptoms and captured debris in EPD was observed in various studies, ${ }^{3-17}$ the utility of the existing classification for guiding treatment was not studied. This classification system has limitation in view of its utility to assess risk of embolism and microembolism.

Hence there is a need for an updated classification, which can be used as a marker in categorizing cases into high and low risk. The classification should be simple, which can help in assessing the plaques that are prone for microemboli. Therefore, an updated classification system is attempted in this work on HR USG combining the high- and low-risk predictors of plaque as mentioned and suggested in various studies..$^{11-17}$

The updated classification has considered plaque echogenicity, calcification, plaque ulceration, IPH, and plaque vascularity for scoring the plaque as low and high risk (demonstrated in $\mathbf{- T a b l e ~ 2 )}$.

- IPH: Defined as well-defined echogenic area within plaque with surrounding echolucency.

- Plaque ulceration: Defined as considering any concavity with an echogenic line at the plaque base or concavity $>2 \mathrm{~mm}$ depth with vascularity within concavity.

- Low-risk plaque: Defined as score $\leq 4(\leq 4)$

- High-risk plaque: Defined as score $\geq 5(\geq 5)$

The updated classification system has the following advantages:

- It has scoring system and hence objective method.

- It has considered all common predictors of unstable plaque.

- It has utility to identify the patients prone for microembolism and associated stroke such as symptoms.

- It will guide treatment in patient with carotid artery stenosis.

This study observed significant association of high-risk plaques with symptom and captured debris $(p<0.0001, S)$ and low-risk plaque in asymptomatic patients with absent captured debris ( $p=0.0001, \mathrm{~S}$ ) when plaque morphology was classified according to updated classification. The ulceration and hemorrhage (-Figs. 2, 3) were $100 \%$ sensitivity parameter whereas calcification was most specific predictor for classification of plaque according to updated classification. The accuracy of calcification was observed 93\%. Calcification was observed most important parameter for predicting microembolism (sensitivity $97.3 \%$, specificity $92.31 \%$, PPV $85.71 \% \%$, NPV 98.63\%, accuracy $93.91 \%)$. The sensitivity of plaque vascularity and ulceration for identifying captured debris was observed $100 \%$ and $97 \%$.

In this observed study, hypertension was most common comorbid condition associated with high-risk plaque followed by smoking and diabetes mellitus. This study observed high-risk plaque between 55 and 64 years of age group, followed by 65 to 74 years of age group. Tallarita et $\mathrm{al}^{18}$ in their study observed mean age of $71 \pm 9$ years. Barbato et $\mathrm{al}^{3}$ observed mean age of $78.6 \pm 9$ years. Fanelli et $\mathrm{al}^{19}$ observed mean age of $68.8 \pm 2.3$ years with the age range of 63 to 85 years. In our study, a maximum number of patients were seen in 55 to 64 years (45\%) and 65 to 74 years (28\%) of age group consisting of total 85 patients (73\%), which suggests an increase in the number of carotid artery stenosis with increase in age. We observed mean age of $61.9 \pm$ 8.27 years with the age range of 46 to 88 years. Our study showed male predominance with $76(66 \%)$ males and 39 (34\%) females. Tizino et $\mathrm{al}^{18}$ and Fanelli et al ${ }^{19}$ showed male predominance. The male predominance is probably due to protective effect of hormones in females.

In our study, the distribution of affected side is equal (right side involvement was seen in $50.43 \%$ and left side involvement was seen in 49.57\%). In our study, on USG and DSA, there was predominance of stenosis of $>70 \%$ seen in $100(87 \%)$ patients. In this study, there was almost equal distribution of high- and low-risk plaque in stenosis $>70 \%$ on USG whereas there was predominance of high-risk plaque (10/15) in stenosis of 50 to $70 \%$. Similar findings are also noted on DSA that is supported on same result basis by Aldemir et $\mathrm{al}^{20}$ and Fanelli et al. ${ }^{19}$

Table 2 The updated classification

\begin{tabular}{|c|c|c|c|c|c|}
\hline Character/score & 0 & 1 & 2 & 3 & 4 \\
\hline $\begin{array}{l}\text { Echogenicity } \\
\text { (Giannakopoulos et al } \\
2012)^{15}\end{array}$ & & Uniformly echogenic & $\begin{array}{l}\text { Predominantly } \\
\text { echogenic with } \\
\text { small area of } \\
\text { echolucency }\end{array}$ & $\begin{array}{l}\text { Substantially } \\
\text { echolucent with } \\
\text { small area of } \\
\text { echogenicity }\end{array}$ & $\begin{array}{l}\text { Predominantly } \\
\text { echolucent }\end{array}$ \\
\hline $\begin{array}{l}\text { Calcification (Simonetti et } \\
\text { al 2013) }\end{array}$ & & $\begin{array}{l}\text { Calcification }>30 \% \text { of } \\
\text { plaque/calcification } \\
\text { at base }\end{array}$ & Calcification < 30\% & $\begin{array}{l}\text { Small calcification } \\
\text { protruding into } \\
\text { lumen }\end{array}$ & No calcification \\
\hline $\begin{array}{l}\text { Plaque ulceration } \\
\text { (ten Kate et al 2013) }{ }^{17}\end{array}$ & Absent & Present & & & \\
\hline $\begin{array}{l}\text { Intraplaque hemorrhage } \\
\text { (Mono et al 2012) }^{11}\end{array}$ & Absent & Present & & & \\
\hline $\begin{array}{l}\text { Vascularity (Brinjikji et al } \\
2015)^{16}\end{array}$ & Absent & Present & & & \\
\hline
\end{tabular}

Definitions. ${ }^{20,25,26}$ 


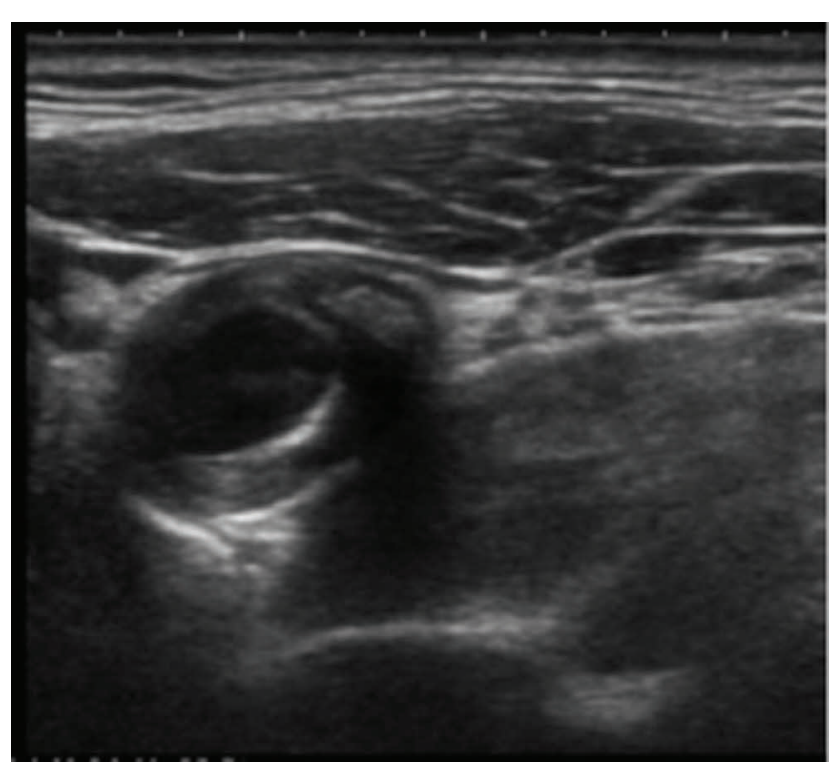

Fig. 2 Transverse B-mode image shows intraplaque hemorrhage (identified as echogenic area within plaque). Existing classificationstable, updated classification high-risk plaque.

Similar to the observation mentioned by Aldemir et a ${ }^{20}$ that vulnerable plaques significantly higher in the symptomatic early CAS group $(25 / 39,64.1 \%)$ than in the symptomatic delayed CAS group $(26 / 58,44.8 \% ; p<0.048)$ or the asymptomatic CAS group (14/44, 31.8\%; $p<0.003)$. Similar findings were also seen by Falkowski et al ${ }^{14}$ who observed stroke in symptomatic than asymptomatic plaques ( $42 \%$ vs. $29 \%, p<0.02$ ) and in echolucent than echogenic plaques (mean GSM of 37.8 vs. $29.7, p<0.01$ ), and plaques with gray-scale median $(\mathrm{GSM}) \leq 32$ were associated with a higher incidence of cerebral infarction as compared with those above this level.

In our study, technical success in terms of filter insertion and retrieval and stent placement was achieved in all cases $(100 \%)$. Fanelli et $a \mathrm{l}^{19}$ achieved technical success of filter placement and retrieval and stent placement in 100\% patients. Similar results were also observed by Baldi et $\mathrm{a}^{21}$ who observed technical success for EDP placement and retrieval in 253 of (99\%) 255 patients, and primary stent placement was successful in 248 of (98\%) 253 patients as shown in - Fig. 4A-E.
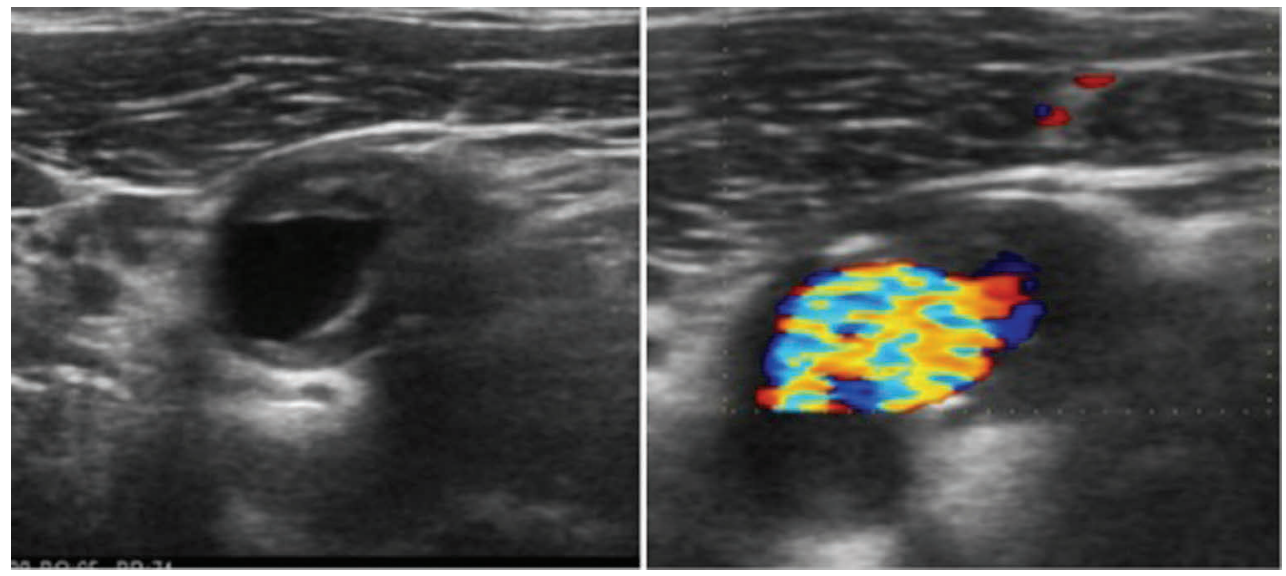

Fig. 3 Transverse B-mode image shows plaque ulceration. According to existing classification-stable, updated classification high-risk plaque. 

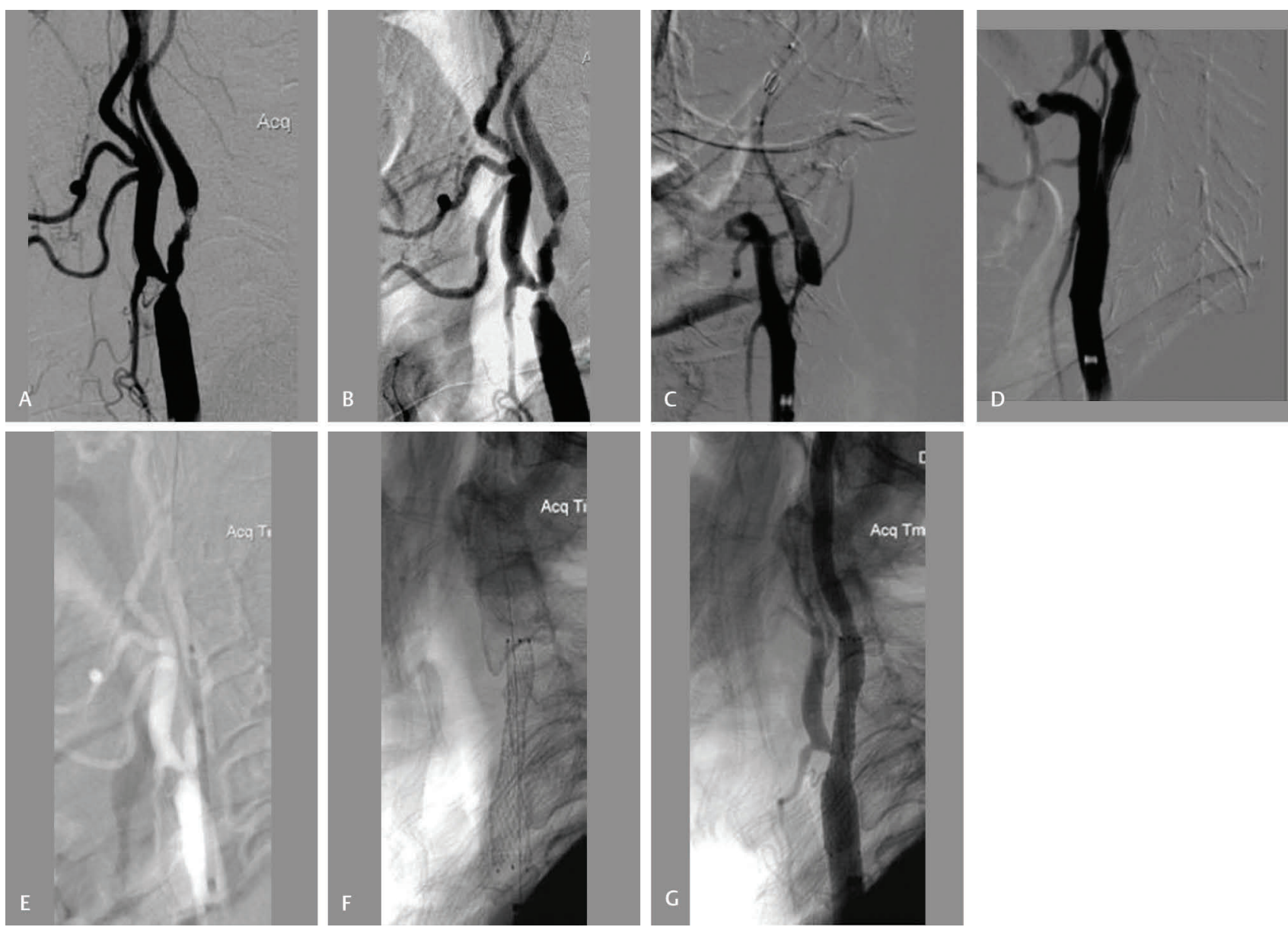

Fig. 4 DSA (digital subtraction angiography) images (A, B) show irregular ulcerated plaque in internal carotid artery (ICA) causing critical stenosis. DSA images (C, D) show distal filter protection device (DFPD) in straight course of ICA, and image (B) shows successful implantation of stent. DSA images (E-G) show shuttle sheath with stent during deployment of stent with DFPD. Images (E) and (F) show successful implantation of stent with post-stenting good flow.

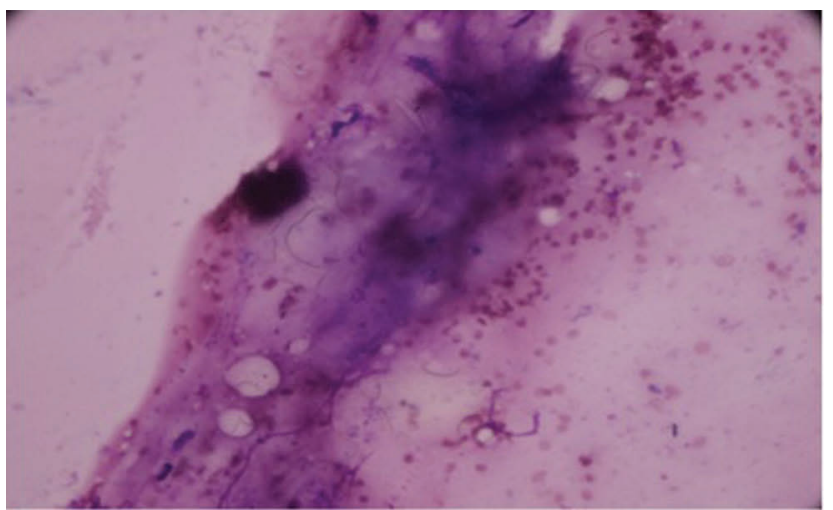

Fig. 5 Photomicrograph cytologic preparation of debris shows the lipid plaque with entrapped lipid vesicles, fibrin, and trapped leukocytes. (Giemsa stain 40x)

\section{Scope}

- Present plaque morphology classification is useful for categorizing the carotid artery disease and thereby useful to guide utility of DFPD.

- Immunohistopathological analysis of debris may be used for assessing potential risk of recurrence of disease.
- Histopathologic analysis and classification of debris can be used as prognostic indicator for therapy of carotid stenosis.

- Adverse effects on cognitive function of the brain due to microembolism $<100 \mu \mathrm{m}$, which are not captured required further evaluation in patient undergoing CAS with EPD.

\section{Conflict of Interest}

None.

\section{References}

1 Lloyd-Jones D, Adams RJ, Brown TM, et al. Heart disease and stroke statistics-2010 update: a report from the American Heart Association. Circulation 2010;121:46-215

2 Haq S, et al. Retrospective evaluation of extracranial carotid artery in patients of acute ischemic stroke. J Clin Diagn Res 2017;11(3):1-5

3 Barbato JE, Dillavou E, Horowitz MB, et al. A randomized trial of carotid artery stenting with and without cerebral protection. J Vasc Surg 2008;47(4):760-765

4 Ouriel K, Wholey MH, Fayad P, et al. Feasibility trial of carotid stenting with and without an embolus protection device. J Endovasc Ther 2005;12(5):525-537 
5 Cosottini M, Michelassi MC, Puglioli M, et al. Silent cerebral ischemia detected with diffusion-weighted imaging in patients treated with protected and unprotected carotid artery stenting. Stroke 2005;36(11):2389-2393

6 Brightwell RE, Ryder TA, Hamady M, Cheshire NJW. Size and nature of emboli produced during carotid artery angioplasty and stenting: in vivo study. Int J Surg 2011;9(2):177-182

7 Kambayashi Y, Yuki I, Ishibashi T, et al. Immunohistochemical analysis of debris captured by filter-type distal embolic protection devices for carotid artery stenting. J Stroke Cerebrovas Dis 2017;26(4):816-822

8 Reid JM, Spencer MP. Ultrasonic Doppler technique for imaging blood vessels. Science 1972;176(4040):1235-1236

9 Barber FE, Baker DW, Nation AWC, Strandness DE Jr, Reid JM. Ultrasonic duplex echo-Doppler scanner. IEEE Trans Biomed Eng 1974;21(2):109-113

10 Blackshear WM, Phillips DJ, Chikos PM, Harley JD, Thiele BL, Strandness DE Jr. Carotid artery velocity patterns in normal and stenotic vessels. Stroke 1980;11(1):67-71

11 Mono M-L, Karameshev A, Slotboom J, et al. Plaque characteristics of asymptomatic carotid stenosis and risk of stroke. Cerebrovasc Dis 2012;34(5-6):343-350

12 Geroulakos G, Ramaswami G, Nicolaides A, et al. Characterization of symptomatic and asymptomatic carotid plaques using high-resolution real-time ultrasonography. Br J Surg 1993;80(10):1274-1277

13 Mathiesen EB, Bønaa KH, Joakimsen O. Echolucent plaques are associated with high risk of ischemic cerebrovascular events in carotid stenosis: the tromsø study. Circulation 2001;103(17):2171-2175

14 Falkowski A, Parafiniuk M, Poncyljusz W, Kaczmarczyk M, Wilk G. Ultrasonographic and histological analysis of atheromatous plaques in carotid arteries and apoplectic complications. Med Sci Monit 2007;13(Suppl 1):78-82

15 Giannakopoulos TG, Moulakakis K, Sfyroeras GS, et al. Association between plaque echogenicity and embolic material captured in filter during protected carotid angioplasty and stenting. Eur J Vasc Endovasc Surg 2012;43(6):627-631

16 Brinjikji W, Huston J, Rabinstein AA, Kim G-M, Lerman A, Lanzino G. Contemporary carotid imaging: from degree of stenosis to plaque vulnerability. JNS 2015:142-452
17 ten Kate GL, van Dijk AC, van den Oord SC, et al. Usefulness of contrast-enhanced ultrasound for detection of carotid plaque ulceration in patients with symptomatic carotid atherosclerosis. Am J Cardiol 2013;112(2):292-298

18 Tallarita T, Rabinstein A, Cloft $\mathrm{H}$, et al. Are distal protection devices 'protective' during carotid angioplasty and stenting? Stroke 2011;42(7):1962-1966

19 Fanelli F, Boatta E, Cannavale A, et al. Carotid artery stenting: analysis of a 12-year single-center experience. J Endovasc Ther 2012;19(6):749-756

20 Aldemir E, Apaydin M, Varer M, Uluc E. Echolucency of carotid plaques and cerebrovascular events. J Clin Ultrasound 2012;40(7):399-404

21 Baldi S, Zander T, Rabellino M, González G, Maynar M. Carotid artery stenting without angioplasty and cerebral protection: a single-center experience with up to 7 years' follow-up. AJNR Am J Neuroradiol 2011;32(4):759-763

22 Bosiers M, Peeters P, Verbist J, et al. Belgian experience with FilterWire EX in the prevention of embolic events during carotid stenting. J Endovasc Ther 2003;10(4):695-701

23 Knur R. Carotid artery stenting with distal filter protection: single-center experience in high-surgical-risk patients. Heart Vessels 2011;26(2):125-130

24 Simonetti G, Schlüter M, Reimers B, Schlüter M, et al. Safety of carotid artery stenting (CAS) with cerebral protection England. J Med 2004;5:146-148

25 Wael ES, Cheng H, Gewertz B, et al. Degree of carotid plaque calcification in relation to symptomatic outcome and plaque inflammation. Presented at the Twenty-seventh Annual Meeting of the Midwestern Vascular Surgical Society, Chicago, IL, September 18-20, 2003.jvs.2004.04.025

26 Safian RD, Jaff MR, Bresnahan JF, et al. CREATE SpideRX Trial Investigators. Protected carotid stenting in high-risk patients: results of the SpideRX arm of the carotid revascularization with ev3 arterial technology evolution trial. J Interv Cardiol 2010;23(5):491-498 